\title{
Erratum to: Why Does Vomiting Stop a Migraine Attack?
}

\author{
Nu Cindy Chai $\cdot$ Robert E. Shapiro • Alan M. Rapoport
}

Published online: 17 September 2013

(C) Springer Science+Business Media New York 2013

Erratum to: Curr Pain Headache Rep (2013) 17:362

DOI: 10.1007/s11916-013-0362-7

The original version of this article, published in Current Pain and Headache Reports, Volume 17, Issue 8, August 2013, inadvertently reversed the order of a doctor's name in the "Future Directions" section of the paper as Dr. Leone Massimo. The correct name is Dr. Massimo Leone.

The online version of the original article can be found at doi:http://dx.doi. org/10.1007/s11916-013-0362-7

N. C. Chai $(\bowtie)$

Department of Neurology, Johns Hopkins University School of

Medicine, Sheikh Zayed Tower, Room 6005, 1800 Orleans Street,

Baltimore, MD, USA

e-mail: nchai1@jhmi.edu

R. E. Shapiro

Department of Neurological Sciences, University of Vermont

College of Medicine, Burlington, VT, USA

A. M. Rapoport

Department of Neurology, The David Geffen School of Medicine at

UCLA, Los Angeles, CA, USA 